\title{
PANAMÁ EN LA POLÍTICA EXTERIOR DE ESTADOS UNIDOS
}

\section{PANAMA IN U.S. FOREIGN POLICY}

\section{AUTOR}

\section{Najib Abu-Warda}

Profesor de Relaciones Internacionales. Facultad de Ciencias de la Información. Universidad Complutense de Madrid (España)

najibabuwarda@hotmail.com

\section{RESUMEN}

La Política Exterior de Estados Unidos hacia América Latina en general ha estado sostenida en la proclama de Monroe de 1823. Desde entonces hasta la fecha han prevalecido los intereses geopolíticos y de seguridad nacional de Estados Unidos, los que a su vez han adquirido dinamismo en función de las distintas administraciones norteamericanas y de las circunstancias internacionales.

\section{PALABRAS CLAVE}

Política exterior - Estados Unidos - América Latin

\section{ABSTRACT}

In general, the U.S. Foreign Policy toward Latin America has been held in Monroe's proclamation of 1823. From then to the present the geopolitical interests and U.S. national security have prevailed, which in turn have gained momentum as a function of the various U.S. administrations and international circumstances. 


\section{KEY WORDS}

Foreign Policy - United States - Latin America

\section{ÍNDICE}

1. La Política Exterior de Estados Unidos en América Latina.

2. La política norteamericana hacia el canal de Panamá.

3. La estrategia norteamericana en relación al Canal de Panamá:

4. Los tratados Torrijos-Carter.

5. La invasión de Panamá

\section{La Política Exterior de Estados Unidos en América Latina.}

La Política Exterior de Estados Unidos hacia América Latina en general ha estado sostenida en la proclama de Monroe de 1823. Desde entonces hasta la fecha han prevalecido los intereses geopolíticos y de seguridad nacional de Estados Unidos, los que a su vez han adquirido dinamismo en función de las distintas administraciones norteamericanas y de las circunstancias internacionales.

América Latina, ha sido considerada como la continuidad territorial de Estados Unidos, donde debe ejercer su dominio y rechazar posibles conquistas extracontinentales.

"América para los americanos" frase que resume la Doctrina Monroe respecto al continente americano. James Monroe, quien ascendió a la Casa Blanca en 1816, era un partidario convencido del expansionismo. En su mensaje sobre el Estado de la Unión, pronunciado el 2 de diciembre de 1823, anunció los principios políticos de su 


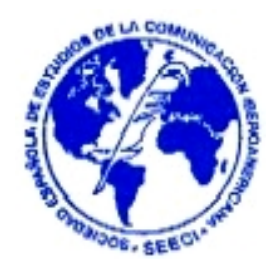

doctrina. Constaba de dos aspectos fundamentales: el principio de la no colonización por ninguna potencia europea en el continente americano; y el principio que consideraba cualquier intervención europea en el hemisferio como una amenaza a la paz y la seguridad de Estados Unidos.

Monroe quería apartar a los europeos de América, por eso afirmaba que había una separación política entre el viejo y el Nuevo Mundo, por ello no cabía la extensión de la influencia política europea, ni tampoco su intervención en los asuntos de América Latina.

La Doctrina Monroe marcó durante más de cien años las relaciones de Estados Unidos con América Latina.

A partir de la Guerra con España (1898), la expansión de EE.UU. en América Latina era ya un hecho consumado. Estados Unidos intervenía directamente en los asuntos internos de los países latinoamericanos para extender su hegemonía sobre ellos.

Roosvelt, C., siguiendo los principios de Monroe, aplicó las mismas tendencias de la política exterior destinadas a garantizar el interés nacional de su país en toda la región, eliminando cualquier influencia no americana en el continente.

Más extremista en la aplicación de la doctrina de Monroe fue Wilson (1913-1921), quien, además de intervenir ampliamente en la soberanía de las naciones del Sur, justificaba acciones militares para mantener la estabilidad y aplicaba una política aislacionista de puerta cerrada.

El sentimiento antinorteamericano crecía y se mostró en la Sexta Conferencia Panamericana celebrada en la Habana en 1928. En todas las Conferencias anteriores el Gobierno norteamericano obstruía los temas políticos y únicamente proponía 


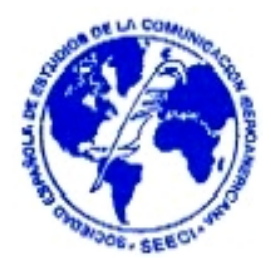

acuerdos comerciales, mientras los latinoamericanos cuestionaban la política intervencionista de Estados Unidos.

La llegada de Roosevelt, Franklin (1933-1945) llevó a ciertos cambios en la política exterior de EE.UU. respecto a América Latina. Su declaración de intenciones el 4 de marzo de 1933 destacó los principios de no intervención y de buena vecindad, principios reafirmados en la Séptima Conferencia Panamericana.

Durante los años de la Segunda Guerra Mundial los países latinoamericanos se aliaron con Estados Unidos ${ }^{1}$ y cooperaron con el $\mathrm{FBI}$ en la detención de agentes alemanes e italianos. Además, Latinoamérica contribuyó con grandes cantidades de materias primas que exportaba a Estados Unidos.

Finalizada la Segunda Guerra Mundial, Norteamérica se convertía en la superpotencia mundial e iniciaba su plena expansión en toda América Latina. Desde entonces los diferentes gobiernos norteamericanos siguieron doctrinas y estrategias destinadas a expandir el Capitalismo y a contener la expansión comunista, a la vez de afirmar su hegemonía mundial. Son los años de la Guerra Fría desde la lucha competitiva de los dos bloques por hacerse con Estados "Satélites". La hegemonía estadounidense sobre Latinoamérica era evidente, una hegemonía que sigue hasta la actualidad.

\section{La política norteamericana hacia el canal de Panamá.}

Desde primeros del año 2000, el Canal de Panamá pasó a ser propiedad del país que le da nombre. Durante sus 88 años de existencia más de 800.000 barcos han cruzado esta vía, cuyo dominio ha llegado a provocar guerras y conflictos y cuyo futuro plantea no menos inquietudes. En efecto, el Canal de Panamá, como uno de los puntos estratégicos de comunicación, constituye un elemento esencial para el

\footnotetext{
${ }^{1}$ Exceptuando Argentina que esperó hasta 1945 debido a su tradición neutral y donde la opinión pública estaba dividida sobre su participación en la Segunda Guerra Mundial.
} 


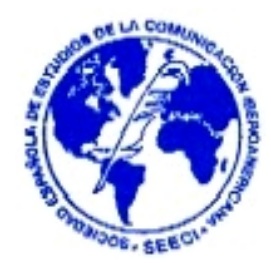

comercio mundial a larga distancia y una de las rutas preferidas por la industria marítima internacional especialmente entre la Costa Oriental de los Estados Unidos y el Lejano Oriente, y entre Europa y la Costa Occidental de los EE.UU. y Canadá.

Desde su construcción, en 1914, se ha convertido en un eslabón fundamental en la cadena del transporte marítimo mundial, y, como consecuencia, en un objetivo estratégico de la política exterior norteamericana.

\section{La estrategia norteamericana en relación al Canal de Panamá:}

La Política exterior de los Estados Unidos hacia Panamá encuentra su justificación en el denominado interés nacional norteamericano de ejercer control sobre la posición geográfica del país. El interés geoestratégico de Estados Unidos con respecto a Panamá se remonta desde tiempos de la independencia de este último. Esto quedó demostrado en el Congreso de Panamá de 1826, Congreso concebido e impulsado por Simón Bolívar que tenía el propósito de unificar a América Latina frente a las pretensiones de Estados Unidos. La Unión Panamá-Colombia, en aplicación del ideal de Bolívar, no tuvo el éxito deseado.

Siguiendo la doctrina Monroe ${ }^{2}$, la política exterior de Estados Unidos niega el derecho de los Estados europeos a celebrar entre sí tratados relativos a las grandes vías de comunicación abiertas en América al comercio y la comunicación internacional. La Doctrina Monroe tuvo especial repercusión respecto al Canal de Panamá. Desde entonces, Panamá, como el resto de Centro América, entró a formar parte de los objetivos estratégicos de Estados Unidos, estrategia que marcó

\footnotetext{
2 1823, 2o reunión del Congreso norteamericano que destacó tres principios: Las potencias europeas no tienen derecho de intervenir en los asuntos internos de los Estados americanos; Toda intervención de esta clase será considerada como hostil y peligrosa para Estados Unidos; La fundación de colonias en América es inadmisible, por hallarse ya repartido todo el continente americano entre Estados civilizados.
} 


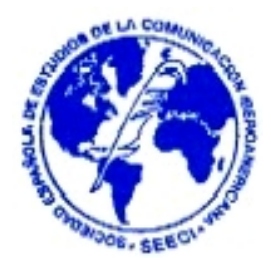

decisivamente la historia política, económica y social del pequeño país en toda su trayectoria desde mediados del siglo XIX hasta la actualidad. A lo largo de estos años, se sucedieron las intervenciones norteamericanas bajo los argumentos de garantizar la estabilidad y el orden político en Panamá.

Dicha política, enfrentó las pretensiones de otra gran potencia, Gran Bretaña, que tenía importantes intereses en la región, lo que se tradujo en beligerancia entre ambas políticas, pero también activó los mecanismos diplomáticos que llevaron a la firma del Tratado Clayton-Bulwer de 1850 que refleja un equilibrio político estableciendo ciertos impedimentos para ambos países en relación a la construcción futura del Canal, es decir, que ninguno de los dos podía emprender unilateralmente la construcción del Canal sin dar participación a la otra. Además, según dichos impedimentos, el Canal debía ser natural ${ }^{3}$.

Desde principios del siglo XX, Estados Unidos surge como potencia marítima importante al adquirir posiciones estratégicas y extender su dominio hacia nuevas áreas. Estas nuevas ambiciones exigían conectar el Atlántico con el Pacífico para facilitar el paso simultáneo de su flota en ambos océanos.

Siguiendo las nuevas exigencias de su "interés nacional", el Presidente McKinley expuso, en su mensaje al Congreso Norteamericano de 1898, la necesidad de construir un canal interoceánico y ponerlo bajo control americano. Esta política fue seguida por Roosevelt quien ejerció enormes presiones contra Colombia, que ejercía soberanía sobre Panamá para obtener la concesión para la construcción del Canal. Al no lograr las necesarias concesiones de Colombia, fomentaron y apoyaron movimientos separatistas que llevaron a la separación de Panamá en noviembre de 1903. Inmediatamente reconocido por estados Unidos, el nuevo Estado firmó, a sólo 15 días de su independencia, el Tratado Hay- Buneau-Varilla el 18 de noviembre de 1903 otorgando a Estados Unidos todos los derechos y privilegios para construir el

\footnotetext{
${ }^{3}$ El Tratado Clayton-Bulwer limitó las pretensiones de Estados Unidos hasta la firma del Convenio Hay-Pruncefote en 1901.
} 


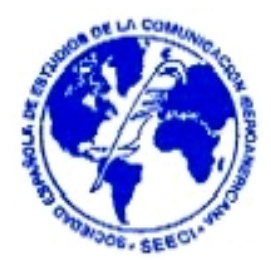

Canal a cambio de que Estados Unidos garantizase la independencia de Panamá. Con este tratado Panamá se convirtió en un protectorado de Estados Unidos ${ }^{4}$.

A través de dicho Tratado, Estados Unidos emprendió la fortificación y militarización del Canal y de sus zonas adyacentes, y le sirvió para intervenir en Panamá en concepto de seguridad del Canal. Tales fueron los casos de 1906, 1918, 1920, 1925 y la invasión de 1989 que reflejan el grado de control y dominio que ejercía estados Unidos sobre el país. Acontecimientos que dificultaron la política bilateral y ayudaron a formar una opinión pública panameña anti-imperialista, cuya evidencia inmediata fue la presión popular que obligó al gobierno panameño a rechazar el Tratado Kellog-Alfaro de 1926, un tratado de vasallaje que pretendía convertir a Panamá en un aliado natural de Estados Unidos. Sin embargo, desde su llegada a la Casa Blanca, el Presidente Roosevelt inició una nueva política hacia Panamá destinada a resolver las diferencias bilaterales y poner en marcha la política de buena vecindad. En este contexto, la firma del Tratado Arias-Roosevelt de 1936 puso fin a la garantía de la independencia de Panamá por parte de Estados Unidos que el tratado de 1903 le otorgó. Además, el nuevo tratado frenó la política norteamericana respecto a la toma indiscriminada de tierras y aguas adicionales al canal. Sin embargo, el propio tratado reconoció el control perpetuo que Estados Unidos ejerce sobre el Canal, incluso facultaba a Estados Unidos para elevar el número de tropas y de bases militares tanto en tiempos de paz como de guerra.

Durante la Segunda Guerra Mundial, Estados Unidos negoció con Panamá la ampliación de las bases militares firmando convenios como el Tratado sobre Arrendamiento de Sitios de Defensa o el Convenio Filos-Hinés, respondiendo ambos a los intereses vitales y de seguridad nacional de Estados Unidos. Sin embargo, ninguno de estos dos convenios fue aprobado debido a las protestas populares antimilitaristas.

\footnotetext{
${ }^{4}$ La Constitución de Panamá de 1904 recoge el contenido del artículo 7 del Tratado Hay-Buneau -Varilla relativo al derecho de intervención.
} 


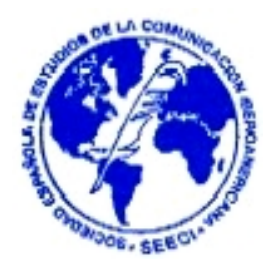

Durante el período de la Guerra-Fría, las necesidades militares de Estados Unidos respondían a una geopolítica global en todas aquellas áreas donde se cuestionaba la hegemonía norteamericana. En aquellos años, América Latina vivió momentos de completa sumisión y el Canal fue utilizado como soporte de sus actividades militares. La Guerra de Corea y de Vietnam son ejemplos evidentes de aquella política. Sin embargo, el éxito de la revolución cubana en 1959 dejó en evidencia la política hegemónica y de seguridad norteamericana en el continente. $Y$ con el fin de limitar los efectos de la experiencia cubana y evitar su extensión en otros países del área, Estados Unidos firmó una serie de tratados de contenido anticomunista con la mayoría de los gobiernos latinoamericanos. Con Panamá se firmó un decreto anticomunista llamado "Junta Interamericana de Defensa" responsable de la defensa del espacio nacional. Sin embargo, la crisis de los misiles en octubre de 1967 y la consiguiente aparición de la doctrina de la Seguridad Nacional, influyeron significativamente en el replanteamiento de la estrategia estadounidense con respecto al Canal. La nueva política canalera dio mayor participación a los militares panameños y mejoró las relaciones bilaterales. En este contexto, a través del Acuerdo Chiari-Kennedy de 1963 se estableció que la bandera panameña debía ser enarbolada en la zona del Canal. Sin embargo, los acontecimientos siguientes demostraron la negativa norteamericana a ceder ninguna competencia real a las autoridades panameñas. Los sucesos de 1964, que causaron 30 muertos y 300 heridos, condujeron a la ruptura de relaciones diplomáticas entre Panamá y Estados Unidos, pero también motivaron el inicio de nuevas formas de diálogo que toman en consideración las demandas nacionalistas y de soberanía de los panameños.

1.

\section{Los tratados Torrijos-Carter.}

Las negociaciones bilaterales sobre el futuro del Canal llevaron a la firma de los Tratados Torijos-Carter en septiembre de 1977. Dichos Acuerdos recogen algunas reivindicaciones panameñas, al tiempo que aseguran a Estados Unidos ciertos derechos en materia de defensa. 


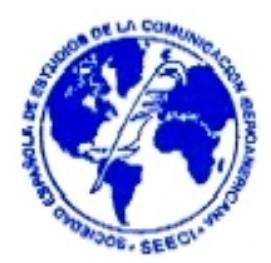

El contenido del Tratado coloca a Panamá como un aliado natural de Estados Unidos y cuestiona la soberanía de Panamá estableciendo la posibilidad de que Estados Unidos extienda sus funciones y presencia militar más allá del año 2000. Además, los términos tan ambiguos en los que fue redactado permiten cualquier tipo de interpretación unilateral y permiten toda acción dirigida a la militarización del Canal y de sus áreas adyacentes, con las implicaciones que se derivan de la presencia militar norteamericana en Panamá. Los términos del Tratado comprometen seriamente la soberanía del país al tiempo que fortalecen la dinámica militar norteamericana.

El Tratado establece la creación de dos mecanismos para la "Defensa conjunta del Canal": la Junta Combinada, compuesta por un número igual de representantes militares de alto rango de Estados Unidos y de Panamá, encargada por sus respectivos gobiernos para consultar y cooperar en todos los asuntos relativos a la protección y defensa del Canal y para planificar las medidas que se tomen para tal fin. El Comité Conjunto que es el mecanismo operativo responsable de administrar las áreas de defensa y de coordinación militar.

Al conocerse el contenido del Tratado por la opinión pública panameña surgieron las primeras protestas y manifestaciones de rechazo y las luchas del pueblo panameño han tenido que enfrentarse al poder imperial, un poder que no duda en ningún momento en invadir el país e imponer sus leyes. Es la invasión de 1989.

\section{La invasión de Panamá}

La vinculación de Panamá a los propósitos militares de EE.UU. fue un elemento determinante en el surgimiento y desarrollo del país. Las circunstancias colonialistas que rodearon el movimiento independentista de 1903 hicieron de Panamá un país mediatizado en su soberanía, es decir, la independencia formal de Panamá estuvo ligada al derecho de intervención de Estados unidos en sus asuntos internos. 


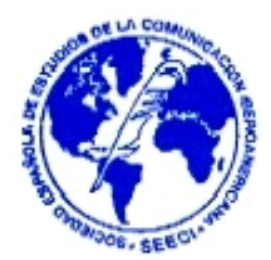

Durante todo el siglo XX, Panamá se enfrentó a las presiones norteamericanas destinadas a convertir al país en un soporte militar e ideológico de los intereses geopolíticos de la gran potencia. La Escuela del Caribe del Ejército en Panamá (U.S. Army Caribbean School in Panamá USA CAIB), llamada posteriormente Escuela de las Américas (USAR-SA), tenía como misión el adiestramiento militar del ejército estadounidense y de otros países latinoamericanos. Sin embargo, la Escuela de las Ameritas ha sido el instrumento más eficiente de las instituciones armadas locales y un conducto y mecanismo de manipulación y control militar de Estados Unidos en países latinoamericanos.

Contra Panamá se han llevado a cabo más de 20 incursiones militares por parte del ejército norteamericano. La invasión de 1989 fue la más cruel y flagrante violación del Derecho Internacional. Todo empezó cuando el 7 de mayo de 1989, Noriega manipuló la victoria de su candidato presidencial Carlos Duque lo que desató una revuelta popular contra el fraude. Se dio una situación de incertidumbre en cuanto al desenlace final. Estados Unidos aumentó sus efectivos militares y activó los ejercicios militares del Comando Sur, maniobras denominadas "para la defensa del Canal".

La cronología de las acciones se desarrolló de manera programada. El plan consistía en duplicar los efectivos en el Canal, proclamar a Guillermo Endara presidente de la República en el área del Comando Sur. Luego Guillermo Endara, en su calidad de Jefe de Estado, solicitaría a Bush su intervención para capturar al General Noriega ${ }^{5}$. Efectivamente, G. Endara juró como presidente en una base militar de EE.UU. El Secretario de Estado, James Baker, declaró que Estados Unidos se reservaba el derecho de invadir Panamá y "restablecer la democracia" en el país. Para la Casa Blanca la acción estaba justificada porque se trataba de proteger a los 35.000 ciudadanos norteamericanos en Panamá, de defender los tratados del Canal, de combatir la droga y los traficantes protegidos por Noriega, y defender la voluntad

\footnotetext{
${ }^{5}$ El Gral. Manuel A. Noriega, J efe de las Fuerzas de Defensa de Panamá, acusó a Estados Unidos de propiciar el fallido golpe de Estado.
} 
soberana del pueblo de Panamá que fuera violada por la anulación de las elecciones por el régimen de Noriega.

La acción militar causó más de 500 muertos y más de 2000 heridos y llevó a la detención de Noriega, que fue condenado a 40 años de prisión en Miami acusado por actos de protección del narcotráfico. La condena fue rebajada en 10 años. Noriega tiene pendientes en Panamá varias condenas por diversos delitos cometidos antes de la invasión.

La invasión de panamá fue criticada en todos los foros internacionales. En el Consejo de Seguridad miembros permanentes como la URSS y China criticaron duramente la invasión y la calificación como una grave violación a la Carta de la ONU. El representante de China calificó la agresión como "acción agresiva de los EE.UU. contra un Estado soberano" que no sólo viola la Carta de la ONU sino también normas y principios básicos del derecho internacional.

Críticas y condenas más duras lanzó el Movimiento de No Alineados que denunciaba el status estadounidense de gendarme internacional y se pedía que su acción fuera condenada por la comunidad Internacional.

Diez años después de la invasión, tuvo lugar la transferencia a Panamá del Canal que lleva su propio nombre. Una transferencia producto del Tratado Torrijos-Carter. Desde el 31 de diciembre de 1999, la administración del Canal está subordinada a leyes y decisiones panameñas. 